\title{
Part-set cuing of order information: Implications for associative theories of serial order memory
}

\author{
MATT SERRA \\ Duke University, Durham, North Carolina \\ and \\ JAMES S. NAIRNE \\ Purdue University, West Lafayette, Indiana
}

\begin{abstract}
In three experiments, the effect of cuing, at the point of test, on memory for order and/or position was investigated. Experiment 1 used a partial reconstruction of order task to demonstrate a mnemonic benefit of part-set cuing at the time of test; this result is used to argue that people may commonly use interitem associative information, rather than just position information, to help them remember serial order. Experiment 2 replicated these findings and simultaneously demonstrated the mnemonic detriment that part-set cuing typically produces in free recall. Experiment 3 showed that cues presented at test will either help or hinder reconstruction of order, depending on whether those cues are consistent or inconsistent with the original presentation order. The results of all three experiments are discussed within the framework of position and associative theories of serial order memory.
\end{abstract}

The ability to remember occurrence information, particularly the position of items in time, is central to successful episodic remembering. When an item is forgotten from a memory list, it is not the item per se that is forgotten but, rather, the fact that the item occurred at a particular point in time. People do not forget the word elephant; they simply forget that elephant occurred on the memory list. Successful remembering, as a result, hinges on the precise encoding and retention of position information - that is, when and where the item occurred in a temporal-spatial window defined by the experiment and its setting (see Crowder, 1979; Estes, 1997; Nairne, 1991).

Traditionally, memory researchers have looked at position memory, or memory for order, by using serial recall tasks, often in an immediate memory setting. A short list of items is presented and followed moments later by a test requiring one to recall the items from left to right in their exact temporal order of presentation. However, immediate serial recall suffers from a number of problems, including the fact that it typically confounds item and order memory; that is, participants need to remember not only the temporal positions that items occupied, but also the items themselves. To help solve this problem, relevant list items can be re-presented at test in a new random order, with the requirement that participants simply place them back into their original order of presentation (e.g.,

We thank Alberder Hampton, Ann Marie Peer, Kelly Pierce, and Andy Robinson for help in collecting and analyzing the data reported here. Also, we thank Robert L. Greene, Stephen Lewendowsky, and Barbara Basden for helpful comments on an earlier version of this manuscript. Correspondence concerning this article should be sent to M. Serra, Department of Psychology: Social and Health Sciences, Duke University, Durham, NC 27708 (e-mail: serram@acpub.duke.edu).
Crowder, 1979; Nairne, 1990). Such reconstruction tests are generally assumed to provide a better overall measure of position memory, as compared with serial recall, although even reconstruction cannot be considered to be a pure measure of position memory (see Nairne \& Neumann, 1993; Neath, 1997).

Empirical studies using reconstruction-as well as studies that employ exactly the same items from one trial to the next - tend to reveal characteristic data patterns. Serial position curves are typically bow shaped, and order errors tend to cluster around an item's originally presented position (e.g., Estes, 1972; Healy, 1974; Nairne, 1991). Moreover, the error gradients, often called positional uncertainty curves, are usually centered around the original position, and they flatten in a systematic and characteristic way with the passage of time. The same general patterns are found when testing occurs immediately after list presentation or when testing is delayed until after several lists have been presented (see Estes, 1997; Nairne, 1992). These regular data patterns are often used as empirical benchmarks for developing theories of serial order memory.

The Estes perturbation model, for example, has been very successful in explaining order data in both shortand long-term settings (Healy, Fendrich, Cunningham, \& Till, 1987; Lee \& Estes, 1977, 1981). The perturbation model assumes that people encode position memories during list presentation (e.g., Item X occurred in the second temporal position on the list) but that those memories become uncertain and fuzzy with the passage of time. More precisely, it is proposed that position memories diffuse along a dimension of temporal position, in accordance with a perturbation process, so that, over time, participants become increasingly more likely to remember positions incorrectly and commit order errors. The perturbation model 
easily handles the benchmark data patterns described above, and it does so in a mathematical form that allows for precise fitting of model to data.

Still, it remains to be seen whether models that rely primarily on the encoding of position memories can really explain all aspects of the data. Historically, of course, associative theories, which posit that people form interitem associations among adjacent items, have been popular alternatives to position accounts (e.g., Ebbinghaus, 1885/ 1964; Lewandowsky \& Murdock, 1989; Murdock, 1983; Shiffrin \& Cook, 1978). Order retention in these models is usually based on a chaining retrieval process, wherein each recovered item serves as a cue for recovering the next item in the sequence. Over the years, concerted efforts have been made to test associative theories in the empirical domain, usually through the use of some kind of transfer design (Jensen, 1962; Young, 1968; see Crowder, 1976, for a review), but these efforts have met with limited success.

The typical transfer experiment involves two stages. First, participants learn a list of stimulus items in a typical serial order memory task. After reaching some performance criterion, they are transferred to the second stage of the experiment, which requires them to learn a second set of stimuli, most often in a paired-associate fashion. Systematic relationships are then arranged between the first and the second lists, in an effort to support one theoretical view over another. For example, cue and target items in the paired-associate task could be constructed out of individual items that were both present in the original study list. Within these pairs composed of previously seen items, the items could then vary as to their contiguity within the original stimulus list. That is, a pair could be made up of contiguous study items (e.g., Items 2 and 3 ) or noncontiguous study items (e.g., Items 5 and 10). On the other hand, pairs could be made up of an individual item from the previous stimulus list and a new unseen item, or a pair could be made up of two new, previously unseen items.

The methodological and theoretical implications of the use of derived pairs in the second task are straightforward. If participants are forming item-to-item associations during the serial learning stage of the experiment, study pairs in the second stage that are composed of items from the original list should lead to criterion level performance more quickly than pairs made up of a mix of old and new items or pairs made up entirely of new items. Furthermore, those pairs consisting of two previously seen items should show a systematic relationship between contiguity of items in the original study list and speed with which criterion level performance is reached; criterion level performance should be reached more quickly for pairs constructed from contiguous rather than noncontiguous original stimulus items (i. e., positive transfer).

Unfortunately, as we noted above, the majority of studies failed to find much evidence for positive transfer (see Young, 1968). The failure to find transfer, in turn, has been taken as evidence supporting position accounts, such as the perturbation model. However, not all transfer studies have yielded null results. Crowder (1968) was able to elicit a positive result with a continuous paired-associate learning paradigm (Peterson, Saltzman, Hillner, \& Land, 1962); participants learned more quickly when adjacent study items were used as pairs in the continuous paired-associate task, and transfer performance increased as the amount of original learning increased (see also Postman \& Stark, 1967). The Crowder (1968) finding is a notable exception to the general pattern of null transfer, and for this reason, it is often used as the main empirical support when associative models of serial recall are proposed (e.g., Lewandowsky \& Murdock, 1989).

Although deciding between position and associative models has always seemed tractable in the empirical domain, through the use of transfer designs and the like, no clear-cut empirical consensus has emerged over the years. Whether one prefers an associative or a position model, at this point, seems to be a matter of taste or of an affinity for the ability of a particular simulation model to handle selected aspects of the data. Our present experiments were designed to present a new empirical attack on this vexing problem. Our evidence will suggest that an associative component may well exist in the encoded representation of serially presented information and that appealing simply to the encoding of position information-as implemented, for example, in the perturbation model-will not be sufficient to explain the data.

The paradigm employed in the following three experiments is a mixture of a methodology used to test order memory, reconstruction (Healy, 1974; Nairne, Riegler, \& Serra, 1991; Serra \& Nairne, 1993), and of a wellestablished memory phenomenon, part-set cuing ${ }^{1}$ inhibition (Slamecka, 1968). In our first experiment, we attempted to see whether the detrimental effect partial cuing has on recall performance with regard to item information would be seen in tests of memory for order. As we will explain shortly, whether one would expect partial cuing to affect position memory has important implications for the position versus associative debate. Our second experiment replicated Experiment 1 while, importantly, demonstrating the normal patterns in free-recall performance that are associated with partial cuing. In Experiment 3 , in turn, we investigated the effects of cuing when test cues are either consistent or inconsistent with the original presentation order.

\section{EXPERIMENT 1}

Experiment 1 was designed to assess the mnemonic effects that might arise in the recall of order information as a result of cuing with a subset of the study items at the time of test. In this experiment, the participants were exposed to a list of eight items followed by a digit-tracking distractor task. At the end of the distractor period, all of the list items were re-presented, in a new random order, but the participants were asked to place only four of the eight items back into their original serial positions. The 
participants were told which of the four target items to position, and they were told which of the eight possible serial positions the target items could occupy. What differed across conditions were the position cues given to the participants: In the cued condition, the four nontarget items were placed back into their original serial positions, and the four available positions were left blank; in the uncued condition, instead of placing the nontarget items back into their original serial positions, these four positions were simply occupied by + signs (see the Appendix).

Notice that item information and serial position information are equated across the two conditions. The only difference is that in the cued condition, people know where the nontarget items originally occurred. From the perspective of a strict position account, such as perturbation theory, this additional information should be of no benefit to order performance. It should help people to know which positions were occupied by targets and which were not, but it should not matter which nontarget items happened to occupy particular nontarget positions. From the perspective of an associative account, however, one would expect a performance advantage in the cued condition. Associative accounts assume that people order stimuli, in large part, on the basis of interitem links-for example, the knowledge that Item A occurred after Item B. Consequently, if a cue is given informing you that Item $\mathrm{A}$ occurred in the second serial position, even if Item $A$ is a nontarget, this will provide you with useful information about where to position Item $B$. There should be a positive effect in the cued condition if participants are relying on interitem associations to complete the reconstruction task.

There is yet a third possibility. It has been well established in other empirical domains that when people are given part-set (or part-list) cues at the point of test, memory performance can be significantly impaired (see Nickerson, 1984, for a review). Experiment 1 is a kind of partset cuing experiment, although we are assessing order rather than item information. To our knowledge, no one has conducted a part-set cuing experiment testing order memory, but we might expect to see an advantage for the uncued over the cued condition from this perspective (see Sloman, Bower, \& Rohrer, 1991, for a possible alternative prediction).

\section{Method}

Participants. Twenty-nine participants took part in this experiment. All received extra credit in an introductory psychology course for their participation.

Design and Materials. This experiment was a complete withinsubjects design. All the participants saw 24 study lists, each followed by a partial reconstruction task. The main manipulation was the type of cue present at the time of test. The participants received either a position cue or an item and position cue configuration. Each list was made up of eight four- to six-letter medium- to high-frequency nouns selected from the Paivio, Yuille, and Madigan (1968) norms. The items were also medium to high with regards to imagery (5.58), meaningfulness (6.37), and concreteness (5.59). All the stimuli were counterbalanced across the main conditions of interest so that each appeared, across participants, as target and nontarget items and in the cued and uncued conditions. All the stimuli were presented on an IBM clone personal computer. Also, all the participant responses were recorded by the computer for later analysis.

Procedure. Each experimental trial began with the word READY presented in the center of the computer screen accompanied by a tone. This word remained on the screen for $2 \mathrm{sec}$ and served to focus the participant's attention on the center of the screen and to indicate that a list of words was about to be presented. Immediately after the word READY left the screen, the study list began. Each list was presented one word at a time, in the center of the screen, for $2 \mathrm{sec}$ per item. As each item appeared on the screen, the participant was required to read the word aloud. After the eighth word left the screen, the participants engaged in a 15-sec-digit-tracking distractor task. Single-digit numbers randomly selected from the set $1-9$ were displayed in the center of the screen at a rate of one digit every $500 \mathrm{msec}$. As each digit appeared, the participant was required to say it aloud.

At the end of the distractor task, the participant performed the partial reconstruction task. On all trials, the eight words composing the just seen study list were re-presented all at once in a single horizontal line across the center of the computer screen. The words in this re-presentation were in a new random order from the one seen previously at study. Immediately underneath four of the study items was a lower case letter (i.e., a, b, c, and d). These letters indicated which four of the eight items were the target items to be placed into their original position. Immediately below the newly randomized study list and its associated letters was a row of eight lines. The participant's task was to place the letters corresponding to the four target items into the four blanks that represented the items' positions in the original study list (see the Appendix for a graphic description of the screen as it appeared to the participants).

On a random one half of the trials, the four lines corresponding to the original serial positions of the four nontarget items had a plus sign $(+)$ in the center of them. This indicated to the participants that the four target items were to be placed in the four remaining blank lines - the four positions that they had held during study. This was considered the uncued condition. On the other random half of the trials, rather than a plus sign being placed in the four nontarget positions, the actual words that held those four positions at study were placed there. Again, this indicated that the four remaining blank lines were the positions that the four target items had held at study. This was considered the cued condition.

The participant's task was to move the cursor, via the arrow keys on the keyboard, to the desired blank and place the letter corresponding to the target item of interest in the blank. The participant then would move to the next blank he or she wished to use and place the proper letter there, and so on. The participants could start at any position they wished and place the items in any order they wished. Each serial position appeared as cued and uncued equally often across the trials. The participants received instructions and two practice trials prior to beginning any experimental trials.

\section{Results and Discussion}

All comparisons noted as significant are so at $p \leq .05$. The mean percentages of correct item placement (the participants' ability to place the target items into their original serial positions) for the two cuing conditions as a function of serial position can be seen in Table 1. These means were placed into a 2 (cued vs. uncued) $\times 8$ (serial position) analysis of variance (ANOVA). The results of the omnibus $F$ test showed a main effect for type of cue $\left[F(1,28)=18.05, M S_{\mathrm{e}}=0.028\right]$ and serial position $\left[F(7,196)=12.47, M S_{\mathrm{e}}=0.024\right]$. The cue type $\times$ serial position interaction was not significant $[F(1,196)=1.80$, $p=.09]$. The main effect of serial position reflects the typical serial position curve one would expect to see in 
Table 1

Proportion of Correct Reconstructions (With Standard Deviations) as a Function of Serial Position and Cue Type

\begin{tabular}{|c|c|c|c|c|c|c|c|c|c|c|c|c|c|c|c|c|c|}
\hline \multirow[b]{3}{*}{ Group } & \multicolumn{16}{|c|}{ Serial Position } & \multirow[b]{3}{*}{ Mean } \\
\hline & \multicolumn{2}{|c|}{1} & \multicolumn{2}{|c|}{2} & \multicolumn{2}{|c|}{3} & \multicolumn{2}{|c|}{4} & \multicolumn{2}{|c|}{5} & \multicolumn{2}{|c|}{6} & \multicolumn{2}{|c|}{7} & \multicolumn{2}{|c|}{8} & \\
\hline & $M$ & $S D$ & $M$ & $S D$ & $M$ & $S D$ & $M$ & $S D$ & $M$ & $S D$ & $M$ & $S D$ & $M$ & $S D$ & $M$ & $S D$ & \\
\hline Cued & .76 & .12 & .63 & .19 & .63 & .19 & .60 & .24 & .50 & .19 & .56 & .19 & .65 & .23 & .65 & .24 & .63 \\
\hline Uncued & .71 & .16 & .62 & .18 & .53 & .20 & .51 & .19 & .50 & .17 & .47 & .18 & .54 & .21 & .58 & .23 & .56 \\
\hline
\end{tabular}

this type of reconstruction task (Nairne, 1991; Serra \& Nairne, 1993).

Clearly, reconstruction performance on the cued trials was better than was reconstruction performance on the uncued trials. This is an important finding because the two conditions were equated on many dimensions: In both conditions, the task was to place four target items from an eight-item list into their originally occurring positions, all eight words were presented at test, and the four target items were clearly marked within the set of eight words. In addition, in both conditions, the participants knew the set of serial positions the four target items occupied. The critical difference between conditions was that in the cued condition, the participants were given the item/position configuration for the nontarget items; in the uncued condition, nontarget item and position information was given, but not their configuration.

It is reasonable to argue that the presence of the item/ position configural cue at the time of test enabled the participants to use whatever item-to-item associative information might have been acquired during study. Simply having item and position information available at test, but not configured into a single cue, was of lesser help in this task. Such a finding creates problems for strict position accounts, such as perturbation theory, that assume that performance is mediated entirely by accessing position information associated with individual items. Perturbation theory assumes that people decide on a position response by simply sampling from an item's positional uncertainty distribution. Information concerning whether other items in the list might have occurred should be irrelevant to performance.

It is interesting to note as well that, in contrast to the mnemonic detriment normally seen for recall of item information in the presence of cue information (see Roediger, Stellon, \& Tulving, 1977; Slamecka, 1968; Sloman, 1991), we see a mnemonic benefit for recall of order information in this task. Although the failure to find evidence of part-set cuing inhibition may be a consequence of our testing of order, it is not without empirical precedent. For example, Slamecka (1975) found that part-set cuing inhibition did not occur in a cued-recognition task. Also, B. H. Basden, D. R. Basden, Church, and Beaupre (1991) showed no part-set cuing inhibition in a fragment completion task. Penney (1988) has argued that intralist. cues might increase recall as long as they tap into the subjective organization created by the participant at encoding. In her experiments, people sorted 64 unrelated items into subjective categories and then recalled the items. For cued trials, 1 item from each subjective unit was given to the participant, and the results showed more items recalled in cued than in uncued conditions (but see Brown $\&$ Hall, 1979, for contradictory results in a similar paradigm). The item position cues given in our situation may well have been consistent with the participant's organizational scheme created at encoding, which could account for the positive cuing effect seen in Experiment 1.

Because of the somewhat confused nature of when one might and might not expect part-set cuing inhibition to occur outside the realm of free recall, it becomes important to establish that the typical mnemonic deficit can be obtained within the context of the present experimental setting. Experiment 2 was designed toward that end, as well as to establish the replicability of the findings of Experiment 1.

\section{EXPERIMENT 2}

Experiment 2 was designed with two objectives. First, we wanted to replicate the reconstruction results seen in Experiment 1. Consequently, on a random half of the experimental trials in Experiment 2, the participants performed the same partial reconstruction task as that used in Experiment 1 with or without the presence of item/position configuration cues. The second goal of the present experiment was to establish that the typical mnemonic detriment seen in free recall when a random set of list cues are provided at retrieval could be replicated in our particular experimental context. Toward that end, on a random half of the experimental trials, the participants were asked simply to free recall the presented items. On half of these recall trials, the participants were presented with four of the eight study list items as cues at the time of test and were told to use the words to help recall the remaining list items. We expected to see the typical mnemonic detriment in this cued condition, as compared with an uncued free-recall condition.

\section{Method}

Participants. Forty-four undergraduate psychology students participated in this experiment. Each received extra credit in an introductory psychology class.

Design and Materials. The same set of 24 eight-item study lists as that used in Experiment 1 was used in this experiment. The manipulation of interest was again administered at the time of the test. On a random one half of the trials, the participants performed the reconstruction task, as outlined in Experiment 1. A random half of 
these trials were cued, and the other half were uncued. On the other half of the trials, the participants were instructed to recall the words in any order. For a random half of these trials, the participants were shown a set of four of the items from the study list to be used as potential cues. The cue items were presented in a random order different from that seen at study. On the remaining free-recall trials, the participants simply were presented a RECALL NOw signal. The order of the four trial types - cued reconstruction, uncued reconstruction, cued free recall, uncued free recall- was randomly determined so that participants would have no way of predicting which trial type would be appearing until the point of test. For both the reconstruction and the recall trials, all the serial positions were cued and uncued equally often, and the materials were rotated through the main experimental conditions across participants.

Procedure. The same procedure for the study session as that in Experiment 1 was used in this experiment. The major difference was that the participants were required to perform reconstruction of order on some trials and free recall on others.

\section{Results and Discussion}

Reconstruction. Again, all of the analyses noted as significant are so at $p \leq .05$. The mean percentages of correct item placement for the two cuing conditions as a function of serial position (i.e., the reconstruction performance) can be seen in Table 2 . The results of a 2 (cued vs. uncued) $\times 8$ (serial position) ANOVA were again clear. The main effect for type of cue $\left[F(1,43)=9.25, M S_{\mathrm{e}}=\right.$ 2.14] replicated the results of Experiment 1. An inspection of the means in the top half of Table 2 demonstrates that the participants showed better performance on the reconstruction trials when the configuration of both item and position information was available at the time of the task. Having position and item information presented separately at test led to poorer performance in the reconstruction task. There was also a main effect of serial position $\left[F(7,301)=15.80, M S_{\mathrm{e}}=1.33\right]$, showing the typical bow-shaped seria: position curve, and the interaction between cue type and serial position was not significant $[F(7,301)=1.27, p=.27]$. These results therefore replicate the basic finding of Experiment 1 , showing a mnemonic benefit for order memory when people are cued with item/position configurations at test.

Recall. For purposes of scoring the free recall, performance in the uncued condition was yoked to that of the cued condition. For example, if a list consisted of the items $\mathrm{ABCDEFGH}$, and the cues $\mathrm{BCGH}$ were given at test, performance in the cued condition would be based only on the recall of the items ADEF; to make the scoring comparable in the uncued condition, even though the participants could recall any item, we scored only the recall of the same subset ADEF. Again, the lists were counterbalanced across conditions, so across participants, the same to-be-recalled items were scored in both the cued and the uncued conditions.

Mean recall by serial position can be seen in the lower half of Table 2 . The data were placed into a 2 (cued vs. uncued) $\times 8$ (serial position) ANOVA, which revealed significant main effects for both the cuing manipulation $\left[F(1,43)=18.23, M S_{\mathrm{e}}=2.02\right]$ and the serial position $\left[F(7,301)=8.07, M S_{\mathrm{e}}=1.27\right]$. The cue type $\times$ serial position interaction also reached significance $[F(7,301)=$ $\left.3.03, M S_{\mathrm{e}}=1.09\right]$. There appeared to be no significant differences between the cued and the uncued conditions at Serial Positions 2-4, whereas performance at Serial Position 1 and Positions 5-8 shows a benefit for uncued trials. Follow-up analyses, using the Dunn correction procedure (see Keppel, 1982), supported this impression: There were no significant differences in performance at Serial Positions $2-4(F \mathrm{~s}<1)$, but there was an advantage for the uncued condition on the remaining serial positions $[F \mathrm{~s}(1,323) \geq 5.42, p \leq .02]$. Consequently, the free-recall data show a quite different pattern from the one found for reconstruction. Rather than a cuing advantage, the results provide, at least, evidence for the typical mnemonic detriment seen in free-recall tasks when part-list cues are presented at test. One possible reason for the recall detriment's being seen at Positions 1 and 5-8 and not at Positions 2-4 is an alteration of the participants' recall strategy. Rather than recalling those items that would normally be recalled, the cues cause a shift to items associated to them at study. However, we made no attempt to record output order in the free-recall condition, so this explanation is speculative. ${ }^{2}$

Overall, the reconstruction and recall results replicate and extend the conclusions of Experiment 1. It helps the recall of order information when participants are given an item/position configural cue at the point of test. As before, we would argue that this might well be due to the participant's formation of interitem associations at encoding, as well as to the participant's ability to make use of these associations at the time of the reconstruction task. In addition, the free-recall results seen in this experiment

Table 2

Proportions of Correct Reconstructions and Recall (With Standard Deviations) as a Function of Serial Position and Cue Type

\begin{tabular}{|c|c|c|c|c|c|c|c|c|c|c|c|c|c|c|c|c|c|}
\hline \multirow[b]{3}{*}{ Group } & \multicolumn{16}{|c|}{ Serial Position } & \multirow[b]{3}{*}{ Mean } \\
\hline & \multicolumn{2}{|c|}{1} & \multicolumn{2}{|c|}{2} & \multicolumn{2}{|c|}{3} & \multicolumn{2}{|c|}{4} & \multicolumn{2}{|c|}{5} & \multicolumn{2}{|c|}{6} & \multicolumn{2}{|c|}{7} & \multicolumn{2}{|c|}{8} & \\
\hline & $M$ & $\overline{S D}$ & $M$ & $\overline{S D}$ & $M$ & $S D$ & $M$ & $S D$ & $M$ & $S D$ & $M$ & $S D$ & $M$ & $S D$ & $M$ & $S D$ & \\
\hline \multicolumn{18}{|c|}{ Reconstruction } \\
\hline Cued & .69 & .21 & .57 & .28 & .52 & .21 & .50 & .21 & .46 & .23 & .47 & .23 & .50 & .21 & .55 & .22 & .53 \\
\hline Uncued & .69 & .19 & .47 & .23 & .41 & .23 & .49 & .26 & .41 & .23 & .44 & .18 & .42 & .21 & .49 & .25 & .48 \\
\hline \multicolumn{18}{|l|}{ Recall } \\
\hline Cued & .31 & .26 & .30 & .22 & .27 & .19 & .26 & .20 & .21 & .23 & .22 & .21 & .37 & .21 & .32 & .21 & .28 \\
\hline Uncued & .44 & .28 & .27 & .18 & .28 & .21 & .28 & .22 & .33 & .22 & .39 & .22 & .46 & .21 & .41 & .23 & .36 \\
\hline
\end{tabular}


argue against any explanation based on some unique characteristic of the experimental paradigm. On half of the trials, the participants were required to perform a simple free-recall task. Exactly which of the trials would be free recall and which would be reconstruction was unknown to the participant until the time of the task. It is, therefore, difficult to argue that the reconstruction results are due to some strategic factor unique to those trials. The results also argue in favor of the viability of this paradigm by demonstrating free-recall results consistent with other experiments examining the part-set cuing inhibition phenomenon.

The next step is to establish experimental results that would bolster our argument that the reconstruction results are due to the participant's use of interitem associations formed at encoding in concert with the item/position cue configuration to complete the task. In Experiment 3, we attempted to do this by setting up a condition in which cue information could help performance, on the one hand, and hurt performance, on the other.

\section{EXPERIMENT 3}

If participants are using interitem associative information to complete the reconstruction task, we should be able to use this fact against them. In the cued condition of the previous two experiments, the cue items were always placed into their correct study list positions at the time of test. This was beneficial, we argued, because it allowed the participants to use the correct placement of Item $A$ in Position $X$ to aid in the placement of Item B in Position $X+1$. In this experiment, we go one step further and allow the participants to use this same type of associative information, but in this case, to the detriment of their reconstruction performance.

On some of the trials in this experiment, the cue words are again placed into one of the serial positions held at the time of study. The difference is that the item is placed into a position that it did not hold at study. For example, if Item $A$ was in Position $X$ at the time of study, it might appear in Position $\mathrm{X}+2$ at the time of test. If the participants are relying on interitem associations formed at encoding to complete the reconstruction task, the placement of Item $A$ in an incorrect position at test should lead to the misplacement of Item B at the time of test.

Again, if participants are relying only on some form of position code established at encoding, misplacement of a cue item at test should have no effect on its neighboring items. As in the previous two experiments, none of the cue items occupied a position that one of the target items held at study. Therefore, by misplacing one of the cue items, we are not taking up one of the slots needed to correctly place the target items.

\section{Method}

Participants. Twenty-four undergraduates participated in this experiment and received extra credit in their introductory psychology class for doing so.

Design and Materials. The manipulation of interest in this experiment was a within-subjects manipulation of cue type administered at the time of the test. There were three levels of the cue type variable. On a random one third of the test trials, the participants were given the position and item information separately, as in the previous two experiments. That is, the target items were clearly marked, and + signs appeared in the serial positions that the nontarget items held at study. This condition was referred to as the control condition in this experiment.

On another random one third of the trials, the participants received the item/position configural cue. That is, four of the original study items were placed in the serial positions that they had held at the time of study. As before, the four target items were clearly marked. This was referred to as the congruent cue condition in this experiment. On the remaining one third of the trials, the participants again received the item/position configural cue. In this case, however, the cue items were randomly placed into one of the four positions that the cue items had held in the original study list but never appeared in the exact positions they had held at study. This was referred to as the incongruent cue condition.

Because of the addition of a third cuing condition in this experiment, an additional set of eight study lists was created. These 64 items were drawn from the same pool as the previous 192 items. All the items were equated with the original study items on frequency, concreteness, imagery, and meaningfulness. Once again, across participants, each list participated in each of the main conditions, and each serial position was cued equally often.

Procedure. The same procedure for both the study and the test sessions as that in Experiment 1 was employed in this experiment. The participants did receive practice with each of the cue types prior to beginning the actual experiment.

\section{Results and Discussion}

Reconstruction. As in the previous two experiments, all of the analyses noted as significant are so at $p \leq .05$. The participant's mean percentages of correct item placement for the three cuing conditions as a function of serial position can be seen in Table 3 . The data were placed into a 3 (cue type) $\times 8$ (serial position) ANOVA. The results of this analysis revealed a significant main effect of both cue type $\left[F(2,46)=20.64, M S_{\mathrm{e}}=3.79\right]$ and serial position $\left[F(7,161)=11.46, M S_{\mathrm{e}}=1.42\right]$. The cue type $\times$ serial position interaction was not significant $(F<1)$.

Table 3

Proportion of Correct Reconstructions (With Standard Deviations) as a Function of Serial Position and Cue Type

\begin{tabular}{|c|c|c|c|c|c|c|c|c|c|c|c|c|c|c|c|c|c|}
\hline \multirow[b]{3}{*}{ Group } & \multicolumn{16}{|c|}{ Serial Position } & \multirow[b]{3}{*}{ Mean } \\
\hline & \multicolumn{2}{|c|}{1} & \multicolumn{2}{|c|}{2} & \multicolumn{2}{|c|}{3} & \multicolumn{2}{|c|}{4} & \multicolumn{2}{|c|}{5} & \multicolumn{2}{|c|}{6} & \multicolumn{2}{|c|}{7} & \multicolumn{2}{|c|}{8} & \\
\hline & $M$ & $S D$ & $M$ & $S D$ & $M$ & $S D$ & $M$ & $S D$ & $M$ & $S D$ & $M$ & $S D$ & $M$ & $S D$ & $M$ & $S D$ & \\
\hline Congruent & .83 & .18 & .66 & .21 & .66 & .22 & .60 & .25 & .60 & .27 & .52 & .28 & .58 & .24 & .58 & .26 & .63 \\
\hline Control & .75 & .23 & .55 & .26 & .54 & .26 & .42 & .33 & .47 & .21 & .50 & .26 & .51 & .28 & .49 & .33 & .53 \\
\hline Incongruent & .60 & .24 & .43 & .25 & .42 & .25 & .37 & .23 & .35 & .25 & .38 & .28 & .36 & .28 & .42 & .23 & .46 \\
\hline
\end{tabular}


A follow-up analysis confirmed what seems evident from the means in Table 3. As in the previous two experiments, having the configuration of the cue items placed into their original study position (congruent cue condition) allowed the participants to perform the reconstruction task significantly better $\left[F(1,46)=11.61, M S_{\mathrm{e}}=\right.$ 3.79] than on the control trials, where both types of information were available but not configurally represented. Performance in the congruent cue condition was also significantly better than performance in the incongruent cue condition $\left[F(1,49)=41.23, M S_{\mathrm{e}}=3.79\right]$, in which the item and position information were configured but in an inaccurate fashion. Also, participant performance on the control trials was significantly better than performance on the incongruent cue trials $[F(1,49)=9.08$, $\left.M S_{\mathrm{e}}=3.79\right]$.

Once again, the findings of Experiment 3 are consistent with the conjecture that people reliably use associative information to remember serial order. Having both item and position information available, but in a nonconfigured fashion, was not as useful to the participants as having the information correctly configured. On the other hand, having the two types of information configured in an inaccurate fashion led to the worst participant performance. This, we would argue, is because the participants use interitem associative information gained at encoding. By having Item A, for example, misplaced into Position $X+1$, the participants used the associative information linking Items $A$ and $B$ when performing the task. This resulted in a misplacement of Item B and the resulting poorer performance on the incongruent trials. ${ }^{3}$

\section{GENERAL DISCUSSION}

With this set of experiments, we have provided evidence consistent with associative accounts of immediate serial recall. In Experiment 1, we demonstrated a mnemonic benefit in a reconstruction task by supplying participants with cues consisting of a configuration of item and order information for half of the study list. In Experiment 2 , we replicated this cuing advantage, while simultaneously demonstrating the typical mnemonic detriment seen in free recall when a random set of list cues is provided at test. In Experiment 3, we provided further evidence of the use of interitem associative information by creating a situation in which the use of such information was both beneficial and detrimental within the same setting.

These results are noteworthy for two major reasons. First, they suggest that purely position-based theories of immediate serial recall will not be sufficient to handle all aspects of the data. Knowing the correct positions of nontarget words helped in the reconstruction of serial order, a finding that is inconsistent with any straightforward positional account. Positional knowledge was equated across the cued and uncued groups, and although it should help one to know the positions that target items did and did not occupy, it should not matter which nontarget items appeared in which serial positions. In reconstructing serial order, people apparently do more than simply sample from an item's positional uncertainty gradient at the point of test (see Estes, 1997; Nairne, 1991).

The second reason these data are important is that they provide empirical support for associative accounts of immediate serial recall (e.g., Jordan, 1986; Lewandowsky \& Murdock, 1989; Wickelgren, 1965). As we discussed earlier, researchers have had a difficult time accumulating solid evidence favoring associative accounts. The majority of transfer studies conducted decades ago failed to find much evidence for positive serial to paired-associate transfer (Young, 1968); recent evidence has provided further challenges, at least to associative accounts based on a chaining retrieval process. For example, Henson, Norris, Page, and Baddeley (1996) closely analyzed serial recall performance for lists composed of alternating confusable and nonconfusable items. Confusable items, as was expected, were recalled less well, but importantly, the presence of confusable items in the list had no effect on the recall of adjacent nonconfusable items. If recall is based primarily on item-to-item cuing, one should have expected lower performance for both the confusable and the nonconfusable item types (see also Baddeley, 1968).

There have also been logical arguments offered over the years against associative chaining (e.g., Jensen \& Rohwer, 1965; Lashley, 1951). For example, chaining accounts have always had difficulty explaining how serial recall performance can be maintained after an error has occurred early in the sequence. If participants fail to recover the appropriate cue, how can performance be correct for the next item in the sequence? Lists containing repeated items pose problems as well: How can the same item serve as an effective cue for two or more distinct items occurring elsewhere in the list? Finally, critics have argued that associative chaining accounts are simply not viable as general theories--they are incapable of explaining the richness of sequential behavior (Lashley, 1951) or the sheer volume of order knowledge (e.g., how a set of associations among 26 letters can account for our memories of many thousands of words; see Hensen et al., 1996).

The data from our present experiments do not speak to most of these issues. The cuing effects seen in our experiments merely demonstrate that people are capable of using item-to-item sequential information to help them remember ordered sequences. This does not mean that associative information is always used to remember serial order or that interitem associations are the sole basis for order recall performance. As we reviewed earlier, there is also a great deal of evidence suggesting that people are capable of remembering and using position information, and there are a number of highly successful models of position memory (e.g., Estes, 1997). It seems likely that people are capable of using multiple kinds of mnemonic information to help them solve order tasks, depending on the circumstance, and models that appeal exclusively to position or interitem associative information are apt to meet with limited success. 
Finally, the data from our experiments are also relevant to the vast literature dealing with cuing effects at the point of test. It has been known for three decades or more that part-set cuing at test can lead to significant impairments in memory performance (e.g., Slamecka, 1968). We were able to find evidence for part-set cuing inhibition, as well as facilitation, in our reconstruction task, but our data are not necessarily inconsistent with existing data and accounts of part-set cuing effects.

Researchers have presented data that show a lack of part-set cuing inhibition in a free-recall procedure when providing congruent cues at test (Sloman et al., 1991). Other researchers have demonstrated part-set cuing facilitation in free-recall paradigms using both categorized (Dong, 1972; Marx, 1988) and unrelated (D. R. Basden, 1973; Blake \& Okada, 1973; Penney, 1988) lists. A number of researchers have argued that intralist cues can aid recall as long as those cues tap into the subjective organization created by the participant at study or the retrieval strategy employed at test (e.g., B. H. Basden et al., 1991; Penney, 1988; Slamecka, 1968). One could easily argue that our item/position configural cues were consistent with an item-to-item associative scheme established during study or with an associative chaining strategy employed at test (D. R. Basden \& B. H. Basden, 1995). Our results support the generality of organization accounts and extend the study of cuing effects to the domain of order information.

\section{REFERENCES}

BADDELEY, A. D. (1968). How does acoustic similarity influence shortterm memory? Quarterly Journal of Experimental Psychology, 20, 249-263.

Basden, B. H., Basden, D. R., Church, B. A., \& Beaupre, P. (1991). Setting boundary conditions on the part-set cuing effect. Bulletin of the Psychonomic Society, 29, 213-216.

BASDEN, D. R. (1973). Cued and uncued recall of unrelated words following interpolated learning. Journal of Experimental Psychology, 98, 429-431.

BASDEN, D. R., \& BASDEN, B. H. (1995). Some tests of the strategy disruption interpretation of part-list cuing inhibition. Journal of Experimental Psychology: Learning, Memory, \& Cognition, 21, 1656-1669.

BLAKE, M., \& OKADA, R. (1973). Intralist cuing following retroactive inhibition of well-learned items. Journal of Experimental Psychology, 101, 386-388.

Brown, A. S., \& HALL, L. A. (1979). Part-list cuing inhibition in semantic memory structures. American Journal of Psychology, 91, 351-362.

CrowDER, R. G. (1968). Evidence for the chaining hypothesis of serial verbal learning. Journal of Experimental Psychology, 76, 497-500.

Crowder, R.G. (1976). Principles of learning and memory. Hillsdale, NJ: Erlbaum.

Crowder, R. G. (1979). Similarity and order in memory. In G. H. Bower (Ed.), The psychology of learning and motivation (Vol. 13, pp. 319353). New York: Academic Press.

Dong, T. (1972). Cued partial recall of categorized words. Journal of Experimental Psychology, 93, 123-129.

Ebinghaus, H. (1964). Memory: A contribution to experimental psy chology (H. A. Ruger \& C. E. Bussenius, Trans.). New York: Dover. (Original work published 1885)

EsTES, W. K. (1972). An associative basis for coding and organization in memory. In A. W. Martin \& E. Martin (Eds.), Coding processes in human memory (pp. 161-190). Washington, DC: Winston.
Estes, W. K. (1997). Processes of memory loss, recovery, and distortion. Psychological Review, 104, 148-169.

HEALY, A. F. (1974). Separating item from order information in shortterm memory. Journal of Verbal Learning \& Verbal Behavior, 13, 644-655.

Healy, A. F., Fendrich, D. W., Cunningham, T. F., \& Till, R. E. (1987). Effect of cueing on short-term retention of order information. Journal of Experimental Psychology: Learning, Memory, \& Cognition, 13, 413-425.

Henson, R. N. A., Norris, D. G., Page, M. P. A., \& Baddeley, A. D. (1996). Unchained memory: Error patterns rule out chaining models of immediate serial recall. Quarterly Journal of Experimental Psychology, 49A, 80-115.

JENSEN, A. R. (1962). Temporal and spatial effects of serial position. American Journal of Psychology, 75, 390-400.

JENSEN, A. R., \& RoHWER, W. D. (1965). What is learned in serial learning? Journal of Verbal Learning \& Verbal Behavior, 4, 62-72.

JORDAN, M. I. (1986). Serial order: A parallel distributed approach (ICS Rep. 8604). San Diego: University of California, Institute for Cognitive Science.

KEPPEL, G. (1982). Design and analysis: A researcher's handbook (2nd ed.). Englewood Cliffs, NJ: Prentice-Hall.

LASHLEY, K. S. (1951). The problem of serial order in behavior. In L. A. Jeffries (Ed.), Cerebral mechanisms in behavior (pp. 112-136). New York: Wiley.

LEE, C. L., \& ESTES, W. K. (1977). Order and position in primary memory for letter strings. Journal of Verbal Learning \& Verbal Behavior, 16, 395-418.

LEE, C. L., \& ESTES, W. K. (1981). Item and order information in shortterm memory: Evidence for multilevel perturbation processes. Journal of Experimental Psychology: Human Learning \& Memory, 7, 149-169.

LEWANDOWSKY, S., \& MURDOCK, B. B., JR. (1989). Memory for serial order. Psychological Review, 96, 25-57.

MARX, M. H. (1988). Facilitation of free recall of category names and instances by indirect part-set cuing. Bulletin of the Psychonomic Society, 26, 195-196.

MurdoCK, B. B., JR. (1983). A distributed memory model for serialorder information. Psychological Review, 90, 316-338.

NAIRNE, J. S. (1990). Similarity and long-term memory for order. Journal of Memory \& Language, 29, 733-746.

NAIRNE, J. S. (1991). Positional uncertainty in long-term memory. Memory \& Cognition, 19, 332-340.

NAIRNE, J. S. (1992). The loss of positional certainty in long-term memory. Psychological Science, 3, 199-202.

Nairne, J. S., \& NeumanN, C. (1993). Enhancing effects of similarity on long-term memory for order. Journal of Experimental Psychology: Learning, Memory, \& Cognition, 19, 329-337.

Nairne, J. S., Riegler, G. L., \& SerRa, M. (1991). Dissociative effects of generation on item and order retention. Journal of Experimental Psychology: Learning, Memory, \& Cognition, 17, 702-709.

NEATH, I. (1997). Modality, concreteness, and set-size effects in a free reconstruction of order task. Memory \& Cognition, 25, 256-263.

NiCKERSON, R. S. (1984). Retrieval inhibition from part-set cuing: A persisting enigma in memory research. Memory \& Cognition, 12, 531-552.

Paivio, A., Yuille, J. C., \& Madigan, S. A. (1968). Concreteness, imagery, and meaningfulness values for 925 nouns. Journal of Experimental Psychology Monographs, 76(1, Pt. 2).

PENNEY, C. G. (1988). A beneficial effect of part-list cuing with unrelated words. Bulletin of the Psychonomic Society, 26, 297-300.

Peterson, L. R., Saltzman, D., Hillner, K., \& Land, V. (1962). Recency and frequency in paired associate learning. Journal of Experimental Psychology, 63, 396-403.

Postman, L., \& STARK, K. (1967). Studies of learning to learn: IV. Transfer from serial to paired-associate learning. Journal of Verbal Learning \& Verbal Behavior, 6, 339-353.

RoEDiger, H. L., III, Stellon, C. C., \& Tulving, E. (1977). Inhibition from part-list cues and rate of recall. Journal of Experimental Psychology: Human Learning \& Memory, 3, 174-188.

Serra, M., \& NaIRne, J. S. (1993). Design controversies and the gen- 
eration effect: Support for an item-order hypothesis. Memory \& Cognition, 21, 34-40.

ShIFFrin, R. M., \& CoOK, J. R. (1978). Short-term forgetting of item and order information. Journal of Verbal Learning \& Verbal Behavior, 17, 189-218.

SLAMECKA, N. J. (1968). An examination of trace strength in free recall. Journal of Experimental Psychology, 76, 504-513.

SLAMECKa, N. J. (1975). Intralist cuing of recognition. Journal of Verbal Learning \& Verbal Behavior, 14, 630-637.

Sloman, S. A. (1991). Part-set cuing inhibition in category-instance and reason generation. Bulletin of the Psychonomic Society, 29, 136138.

Sloman, S. A., Bower, G. H., \& Rohrer, D. (1991). Congruency effects in part-list cuing inhibition. Journal of Experimental Psychology: Learning, Memory, \& Cognition, 17, 974-982.

WICKELGREN, W. A. (1965). Short-term memory for phonemically similar lists. American Journal of Psychology, 78, 567-574.

Young, R. K. (1968). Serial learning. In T. R. Dixon \& D. L. Horton (Eds.), Verbal behavior and general behavior theory (pp. 122-148). Englewood Cliffs, NJ: Prentice-Hall.

\section{NOTES}

1. Technically, all the experiments in this paper deal with the use of part-list cues. However, the term part-set cue is more pervasive in the literature and is often used interchangeably with the term part-list cue. For the sake of continuity, we will use the term part-set cue throughout this paper.

2. We thank Robert Greene for bringing this possibility to our attention.

3. The probability that a target item placed in error was placed in a position immediately following a misplaced cue item with which the target item was contiguous at study was 38 (collapsed across serial position). This is significantly higher than would be expected by chance $[t(23)=5.43, S E=2.45, p<.0001]$.

\section{APPENDIX \\ Example Test Trial as Seen by the Participant on the Computer Screen}

Assume that the study list consisted of the following eight items in this order: WEAPON TABLE DOLLAR CODE APPLE FRIEND WATER SALAD.

All trials ended with the entire list presented in a new random order with lowercase letters associated with four of the items:

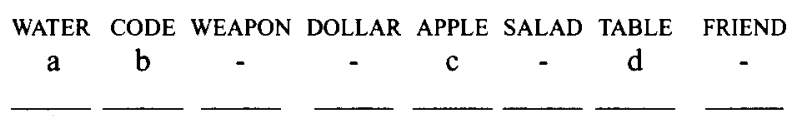

The participant's task was to place the lettered target words into their appropriate original serial positions.

\section{Cued Condition}

On a random half of the trials, the participants were presented with the four nontarget words in their original study positions:

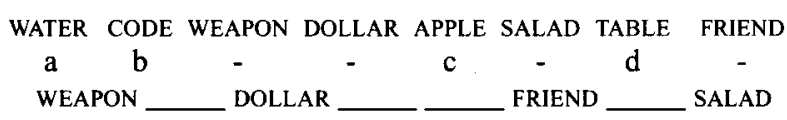

\section{Uncued Condition}

On a random half of the trials, the participants were simply given + signs in the positions held by the nontarget words:

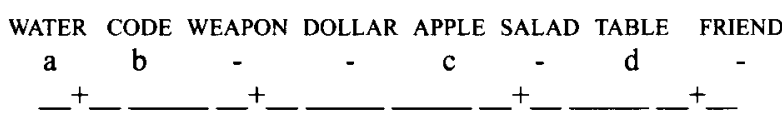

